\title{
Shoaling of large-amplitude nonlinear internal waves at Dongsha Atoll in the northern South China Sea
}

\author{
Ke-Hsien Fu' ${ }^{\mathrm{a}}$, Yu-Huai Wang ${ }^{\mathrm{b}, *}$, Louis St. Laurent ${ }^{\mathrm{c}}$, Harper Simmons ${ }^{\mathrm{d}}$, Dong-Ping Wang ${ }^{\mathrm{e}}$ \\ ${ }^{a}$ Department of Marine Environment and Engineering, National Sun Yat-sen University, Kaohsiung, Taiwan. \\ ${ }^{\mathrm{b}}$ Institute of Applied Marine Physics and Undersea Technology, National Sun Yat-sen University, Kaohsiung, \\ Taiwan. \\ ${ }^{\mathrm{c}}$ Woods Hole Oceanographic Institution, Woods Hole, Massachusetts, USA. \\ ${ }^{\mathrm{d}}$ School of Fisheries and Ocean Sciences, University of Alaska, Fairbanks, Alaska, USA. \\ ${ }^{\text {e }}$ School of Marine and Atmospheric Sciences, Stony Brook University, USA
}

\begin{abstract}
Shoaling of large-amplitude $(\sim 100 \mathrm{~m})$ nonlinear internal waves over a steep slope $\left(\sim 3^{\circ}\right)$ in water depths between $100 \mathrm{~m}$ and $285 \mathrm{~m}$ near Dongsha Atoll in the northern South China Sea is examined with an intensive array of thermistor moorings and a bottom mounted Acoustic Doppler Current Profiler. During the 44-hour study period in May 5-7, 2008, there were four groups of large internal waves with semidiurnal modulation. In each wave group a rapid transition occurred during the shoaling, such that the front face of the leading depression wave elongated and plunged to the bottom and the rear face steepened and transformed into a bottom-trapped elevation wave. The transitions occur in water depths of $200 \mathrm{~m}$ and deeper, and represent the largest documented internal wave shoaling events. The observations repeatedly capture the detailed temperature and velocity structures of the incident plunging waves. Strong horizontal convergence and intense upward motion are found at the leading edge of transformed elevation waves, suggesting flow separation near the bottom. The observations are compared with the previous observations and model studies. The implication of the shoaling internal waves on coral reef ecology also is discussed.
\end{abstract}

keywords: Internal waves, Shoaling, Bottom slope, South China Sea, Continental shelf

\footnotetext{
* Corresponding author: Tel:+88675252055, Fax:+88675255270, E-mail address:yhwang@nsysu.edu.tw
} 


\section{Introduction}

In the northern South China Sea (SCS), large nonlinear internal waves ('internal solitary waves') with amplitudes exceeding150 m have been observed (Klymak et al., 2006). These waves propagate westward across the basin, shoal and dissipate at the shallow continental shelf (Hsu and Liu, 2000; Zhao et al., 2004; Chang et al., 2006; St. Laurent, 2008; Alford et al., 2010). Two types of internal solitary waves have been identified: a-waves that arrive regularly at the same time each day, and b-waves that arrive an hour later each day (Ramp et al., 2004). Model studies suggested that the nonlinear internal waves are evolved from semidiurnal internal tides generated over the ridges in the Luzon Strait (Chao et al., 2007; Shaw et al., 2009; Warn et al., 2010; Zhang et al., 2011; Li and farmer, 2011).

The internal solitary waves begin as large depression waves in the deep basin. As they propagate up the continental slope, they transition into the elevation waves. Liu et al. (1998) found that the elevation waves over the shelf often are marked by a thick bottom mixed layer. Using a modified Korteweg-deVries (KdV) equation, they suggested that the incident depression waves first disintegrate into a dispersive wave train and then evolve into a packet of elevation waves. The critical/turning point occurs approximately at where the upper and lower layers have equal thickness that the nonlinearity coefficient in the $\mathrm{KdV}$ equation changes sign. Also, Hsu and Liu (2000) showed that the transition from waves of depression to elevation could be detected from the satellite remote sensing. The depression waves are marked by the bright and dark bands in the SAR image. The bright band is indicative of the strong surface convergence at the front face of the wave, which causes accumulation of short breaking surface waves. As the waves transition from depression to elevation, the surface patterns reverse to the dark and bright bands. As an example, Figure 1 shows a MODIS image of three groups (A, B, C) of internal solitary waves near Dongsha Atoll in the northern SCS.

Many theoretical and laboratory studies have examined the shoaling of depression waves over a sloping bottom (Helfrich and Melville 1986; Liu et al., 1998; Vlasenko and Stashchuk, 2007). Field studies, on the other hand, have been relatively few, due to difficulties in obtaining high-resolution spatial and temporal sampling. Shroyer et al. (2009), for example, followed a group of nonlinear internal waves as they shoaled over a gentle slope $\left(0.5^{\circ}\right)$, and Bourgault et al. (2007) investigated shoaling of nonlinear internal waves over a steep slope $\left(3^{\circ}\right)$ with a mooring array. These studies are conducted in the shallow water, and the observed 
internal wave amplitudes are small $(\sim 10 \mathrm{~m})$. In contrast, during the Asian Seas International Acoustics Experiment (ASIAEX) in the northern SCS, Orr and Mignerey (2003) followed a group of large-amplitude (40-70 m) internal solitary waves over a gentle slope $\left(1^{\circ}\right)$ on the outer shelf. The leading depression waves were found to disintegrate into a packet of elevation waves in water depths of 150-180 m. These waves were the mode-1 with opposite flows in the upper and lower layers, and the wave polarity changed from counterclockwise over a depression wave to clockwise over an elevation wave. In their study The interface however was in the mid-depth well above the bottom. Duda et al. (2004) described the same shoaling events based on an array of moored thermistor and ADCP moorings.

In this study, we describe rapid transition of large-amplitude nonlinear internal waves up a steep slope $\left(3^{\circ}\right)$ near Dongsha Atoll in the northern SCS based on measurements from a dense array of thermistor moorings and a bottom mounted ADCP. Section 2 describes the field work, section 3 describes the results, and section 4 presents a discussion with comparison to the previous studies.

\section{Observations}

The field study was carried out onboard the Taiwan research vessel Ocean Researcher 3 (OR3) in May 5-7, 2008 on the east side of Dongsha Atoll (Fig. 2). Eight thermistor strings were deployed over a steep slope. Because of heavy fishing activity in the study area, OR3 was stationed around the moorings to prevent fishing vessels from disturbing the field experiment. The moorings were in place for approximately 2 days. Seven moorings were successfully recovered. The analysis was based on five moorings, M1-M5, in water depths between $100 \mathrm{~m}$ and $285 \mathrm{~m}$ (Fig. 2). Data from the other two moorings were corrupted and were not included. There were 46 temperature loggers (13 Star-Oddi DST Centi-TD of accuracy $+/-0.1{ }^{\circ} \mathrm{C} ; 33$ Vemco Minilog 8-bit of accuracy $+/-0.3{ }^{\circ} \mathrm{C}$ ) distributed about evenly on the 5 mooring lines. The vertical resolutions were $20 \mathrm{~m}$ on M1, M2 and M3, and $10 \mathrm{~m}$ on M4 and M5. The sampling rate was set at $30 \mathrm{~s}$. At M3 (water depth $=155 \mathrm{~m}$ ), an upward looking $300 \mathrm{kHz}$ ADCP (RDI Workhorse Sentinel 300) was attached on the mooring line at a depth of $125 \mathrm{~m}$, which sampled velocity profiles every minute with a bin size of 8 m. 


\section{Results}

Figure 3 shows 44-hour temperature records from 16:00 local time (GMT + 8h) May 5 to 12:30 May 7 at M3 . The data were presented in two 24-h panels, following Ramp et al. (2004). In each 'day' (24-h period) there were two groups of large-amplitude nonlinear internal waves of depression. Each group included several large-amplitude (> $100 \mathrm{~m})$ and numerous moderate-amplitude $(\sim 60 \mathrm{~m})$ waves. The semidiurnal period was obvious: the wave groups arriving in the $2^{\text {nd }}$ day were delayed by about an hour or two from the corresponding groups in the first day. The interface (thermocline) was approximately delineated by the $23^{\circ} \mathrm{C}$ isotherm with the mean depth at about $80 \mathrm{~m}$. During the passage of wave packets the warm surface waters sometimes were displaced down to the bottom.

The shoaling of large depression waves was examined based on temperature records from moorings M1-M5 in water depths from $285 \mathrm{~m}$ to $100 \mathrm{~m}$ over a distance of about $5 \mathrm{~km}$. Figure 4 shows a major shoaling event in the evening of May 6. A large depression wave with amplitude of about $80 \mathrm{~m}$ arrived at M1 at 20:40, displacing the thermocline down to almost $200 \mathrm{~m}$ depth. The initial waveform was symmetric. However, as the depression wave shoaled over the steep slope, the waveform went through a dramatic change. While the rear face of the wave ('wave trough') remained steep, the front side ('wave crest') elongated and became paralleled to the bottom topography. The trend continued until the front edge and face of the leading depression wave became unidentifiable and a bottom-trapped elevation wave emerged. The waves remained in elevation form at M2, and evolved into 2-3 distinct elevation waves as they passed through the shallower stations M3-M5. Also, preceding this major event, there were about 15 smaller depression waves. Some of these smaller waves also made transitions as they propagated through M4 and M5.

Figure 5 shows another major shoaling event in the morning of May 7. The large depression wave arrived on 6:00 at M1, and had a symmetric form. This was followed by a rapid transition, marked by broadening of the front face of the leading wave and emergence of a bottom-trapped elevation wave. The sequence was similar to the May 6 event. However, in the previous event the thermocline quickly recovered after the transition, whereas in the present case the thermocline was displaced down to $200 \mathrm{~m}$ after the leading depression wave had passed. Moreover, several large elevation waves emerged at M2 after 8:15 that 
were clearly separated from the leading elevation wave. This suggested that the May 7 event was impacted by a train of large depression waves. The evidence also was indicated in "blow down" of the M1 mooring line between 6:30 and 7:00 after the leading depression wave already had passed. The prolonged event led to an enduring $(\sim 4 \mathrm{~h})$ bottom trapping of warm surface water in M4-M5.

The ADCP at M3 recorded the velocity profiles between $45 \mathrm{~m}$ and $125 \mathrm{~m}$ below the surface. Figure 6 shows an expanded view of temperatures and flow vectors for the May 6 event. The leading depression wave had an elongated wave crest that extended down to the bottom, and the elevation wave was narrow and extruded $100 \mathrm{~m}$ above the bottom. The horizontal velocity was offshore (eastward) in the depression wave, but reversed to onshore in the elevation wave. Strong convergence was formed in the leading edge of the elevation wave, and strong divergence in its trailing edge. The vertical velocity was upward in the convergence zone and downward in the divergence zone. The strong upward motion also was indicated by a sudden burst of acoustic backscatters (not shown), indicating large resuspension of bottom sediment. While there was no velocity measurement in the upper $40 \mathrm{~m}$, the vertical motion indicated a clockwise circulation (positive polarity) associated with the elevation wave, in agreement with the previous studies, e.g., Orr and Mignerey (2003) and Shroyer et al. (2009). We noted that the observed flow pattern is robust. In all four wave groups the transition events were clearly identified by large offshore flows associated with the depression wave, followed by sudden flow reversal with the elevation wave.

The nonlinear internal waves are commonly described in terms of the classical soliton solution of the Korteweg-deVries (KdV) equation. To convert the time axis at a fixed mooring into the distance, it is necessary to estimate the wave phase speed. The mooring section was oriented $282^{\circ}$ (true north), based on the previous study in ASIAEX (Ramp et al., 2004), and was approximately perpendicular to the wave front indicated in the MODIS image taken on 13:25, May 7 (Fig. 1). Also, the incident waves are expected to bend (refract) parallel to the shelf edge as they approach the Dongsha Atoll (Zhao et al., 2008). The phase speed therefore could be reliably estimated by following the wave front across the mooring section. The $23^{\circ} \mathrm{C}$ isotherm was used to delineate the interface, and the wave trough was tracked through the 5 stations. The estimated phase speeds were $1.05,0.74,0.76$, and $0.43 \mathrm{~m} / \mathrm{s}$, respectively for the four sections between the neighboring moorings. Figure 7 shows the resulting spatial structures for the May 6 event. The amplitude 
and wavelength of the depression and elevations waves also were fitted to the KdV solution $\eta=\eta_{0} \sec h^{2}(x / L)$. The depression wave at M1, for example, had $80 \mathrm{~m}$ amplitude $(\eta)$ and $1500 \mathrm{~m}$ wavelength (L). Figure 8 summarizes the characteristics of all four groups of shoaling waves. The statistics include the wave amplitude, wavelength, and phase speed. The incident depression waves at M1 had amplitudes ranging from 70 to $110 \mathrm{~m}$ and wavelengths from 1500 to $2300 \mathrm{~m}$. The amplitudes decreased to $50 \mathrm{~m}$ at M2 and M3, and $15 \mathrm{~m}$ at M4 and M5. The wavelength also decreased from $2000 \mathrm{~m}$ at M1 to $1000 \mathrm{~m}$ at M3 and $300 \mathrm{~m}$ at M5. These results are consistent with Bourgualt et al. (2007) who found that the wave properties remain almost constant prior to the transition but decrease rapidly afterward.

For long, weakly nonlinear internal waves in a two layer system, the phase speed of a soliton based on the $\mathrm{KdV}$ equation is given by

$$
C=c_{o}+\frac{\eta_{o}}{3} \alpha
$$

where $c_{o}$ is the linear phase speed and $\alpha$ is the coefficient of nonlinearity

$$
c_{0}{ }^{2}=\frac{g h_{1} h_{2}\left(\rho_{2}-\rho_{1}\right)}{h_{2}+h_{1}}, \quad \alpha=\frac{3 c_{0}}{2} \frac{h_{1}-h_{2}}{h_{1} h_{2}}
$$

and $h_{1}\left(h_{2}\right)$ and $\rho_{1}\left(\rho_{2}\right)$ are the depth and density of the upper (lower) layer, $\mathrm{g}$ is the gravitational constant. The densities were estimated from the hydrography measured on May 7. The computed phase speeds are 1.12 $\mathrm{m} / \mathrm{s}$ at $\mathrm{M} 1,0.78 \mathrm{~m} / \mathrm{s}$ at $\mathrm{M} 2,0.8 \mathrm{~m} / \mathrm{s}$ at $\mathrm{M} 3$, and $0.49 \mathrm{~m} / \mathrm{s}$ at $\mathrm{M} 4$, which compare well with the empirically estimated phase speeds (Fig. 8).

The depth-integrated horizontal energy flux of internal waves is estimated from the wave phase speed and energy density, $F=c\langle K E+A P E\rangle$, where $c$ is phase speed (Klymak et al., 2006; Moum et al., 2007). The depth-integrated kinetic energy density is given by

$$
K E=\frac{1}{2} \int \rho_{o}\left\langle u^{2}+v^{2}+w^{2}\right\rangle d z
$$

where $\rho_{\mathrm{o}}$ is the reference density, $(u, v, w)$ are the three velocity components, and the bracket is average over a wavelength. The depth range is from 25 to $155 \mathrm{~m}$ below the surface. The depth-integrated available potential energy (APE) density is calculated following Vallis (2006), 


$$
A P E_{1}=\int \frac{1}{2} g\left\langle(z(\rho)-\bar{z}(\rho))^{2}\right\rangle d \rho
$$

where $z$ is the height of an isopycnal surface, and the overbar indicates the background value. In evaluating $A P E$ in the density coordinate, the background state of minimum potential energy can be simply defined as the level isopycnal surfaces. The vertical integration is over the density range from 1023.2 to $1025.4 \mathrm{~kg} / \mathrm{m}^{3}$, or equivalently in the temperature range between 16.2 and $24{ }^{\circ} \mathrm{C}$. The $A P E$ density also is calculated following Holliday and McIntyre (1981),

$$
A P E_{2}=\iint_{z-\varsigma}^{z} g\left\langle\rho(z)-\bar{\rho}\left(z^{\prime}\right)\right\rangle d z^{\prime} d z
$$

where $\zeta$ is the vertical displacement of a fluid particle from its origin. $A P E_{1}$ and $A P E_{2}$ are both positive-definite and reduce to the same classical linear limit. $A P E_{2}$ however is subject to the small displacement approximation.

The $A P E$ density was calculated for the May 6 event. The incident wave was a depression wave at M1 but transitioned to an elevation wave afterwards (Fig. 7). The $A P E_{1}\left(A P E_{2}\right)$ integrated over a single wavelength were 18.8 (19.5), 9.7 (9.5), 4.1 (5.2), and 1.1 (1.4) MJ/m for M1, M2, M3, and M4, respectively. The $A P E$ decreased rapidly, indicating significant dissipation. We noted however since the $A P E$ estimate was for a single wave, part of the $A P E$ decrease could be attributed to the dispersion of elevation waves; for example, the elevation wave split into two at M4. Also, part of the incident wave energy might be reflected. The $K E$ density for M3 was about $6.9 \mathrm{MJ} / \mathrm{m}$. The $K E$ estimate was biased low due to the absence of velocity measurements in the upper $40 \mathrm{~m}$ and the lower $20 \mathrm{~m}$. Assuming the missing portion contributed to an additional $20 \%$ of $K E$, the energy ratio $\langle K E\rangle /\langle A P E\rangle$ was about 2 for the May 6 event. For comparison, Moum et al. (2007) obtained an energy ratio of 1.04 for bottom trapped waves on the Oregon's continental shelf, and Klymak et al. (2006) found a ratio of 1.4 for elevation waves in the northern South China Sea. Using the estimated energy ratio and the observed phase speed, the energy flux at M3 was about $30 \mathrm{~kW} / \mathrm{m}$. For comparison, St. Laurent (2008) found maximum energy flux of about $8 \mathrm{~kW} / \mathrm{m}$ during 12-h time series measurements in the upper slope at ASIAEX.

\section{Discussion}


The intensive mooring observations east of Dongsha Atoll have documented a dramatic waveform transformation of the large-amplitude nonlinear internal waves shoaling over a steep slope. The observations provide, for the first time, detailed temperature and velocity structures of a collapsed depression wave. Our observations are in qualitative agreement with numerical model simulations of shoaling of large-amplitude internal waves (Liu et al., 1998; Vlasenko and Stashchuk, 2007). The broadening of front face of leading waves, emergence of multiple elevation waves, and the clockwise circulation of elevation waves are consistent with the model prediction. The observed strong offshore flow in the collapsed wave however contradicts the expected onshore flow of a shoreward propagating mode- 1 depression wave. The discrepancy likely is the result of a vanishing interface during the transition. As the leading depression wave plunges to the bottom the lower-layer offshore flow has to escape, which probably produces an offshore return flow. Vlasenko and Hutter (2002) had attempted to simulate a collapsing internal solitary wave over a sloping shelf. However, the incident wave in their model becomes unstable and overturns before the flow separation could take place.

Two types of nonlinear internal waves had previously been identified: a-waves that arrive regularly at the same time each day, and b-waves that arrive an hour later each day (Ramp et al., 2004; Ramp et al., 2010). The a-waves are larger and have a rank-ordered packet structure, whereas the b-waves generally are smaller and often consist of a single solitary wave. The observed nonlinear internal waves do not seem to fit either wave type: they arrive in packets similar to the a-waves, but are delayed by an hour or two from the previous day similar to the b-waves. This suggests that the internal wave climate in the northern SCS perhaps is more complex than deduced from the observations that were taken further north. Our measurement though covers a very short period ( $44 \mathrm{~h})$, and might not be representative. To clarify this apparent disagreement requires much longer time series observations.

The bottom-trapped elevation waves could have important implication for coral reef ecology (Leichter et al., 2005; Baker et al., 2008). The smaller ( 30-m amplitude) internal waves would propagate into much shallower water and transform to the elevation waves. Since small-amplitude waves are abundant, this could provide an effective mechanism to 'pump' bottom water to the nearshore region. Upwelling of nutrient-rich subsurface water could be important in maintaining reef community at Dongsha Atoll. The frequent cold 
intrusions may also help to protect coral reefs from abnormal surface heating. During the 1997-1998 El Niño, corals in the lagoon of Dongsha Atoll were severely damaged; yet perplexingly, corals in the shallow reef slopes facing the open basin remained healthy (Wang et al., 2007). It has been suggested that larvae living in the fluctuating thermal regimes might be physiologically well suited to the more extreme temperature variations (Putnam et al., 2010).

\section{Acknowledgements}

We would like to thank the officers and crew of research vessel Ocean Researcher 3. Fruitful comments from two anonymous reviewers are appreciated. This work is supported by the National Science Council and the Aim for Top University Plan Project, Taiwan. Support for LS and HS came from the US Office of Naval Research. 


\section{References}

Alford, M.H., Lien, R.C., Simmons, H., Klymak, J., Ramp, S.R., Yang, Y.J., Tang, T.Y., Chang, M.H., 2010. Speed and evolution of nonlinear internal waves transiting the South China Sea. Journal of Physical Oceanography 40 (6), 1338-1355.

Baker, A. C., Glynn, P.W., Riegl, B., 2008. Climate change and coral reef bleaching: An ecological assessment of long-term impacts, recovery trends and future outlook, Estuarine, Coastal and Shelf Science 80, 1-37, doi:10.1016/j.ecss.2008.09.003.

Bourgault, D., Blokhina, M.D., Mirshak, R., Kelley, D.E., 2007. Evolution of a shoaling internal solitary wavetrain. Geophysical Research Letters 34, L03601, doi:10.1029/2006GL028462.

Chang, M.H., Lien, R.C., Tang, T.Y., D’Asaro, E.A., Yang, Y.J., 2006. Energy flux of nonlinear internal waves in northern South China Sea. Geophysical Research Letters 33, L03607, doi:10.1029/2004GL022012.

Chao, S.Y., Ko, D.S., Lien, R.C., Shaw, P.T., 2007. Assessing the west ridge of Luzon Strait as an internal wave mediator. Journal of Oceanography 63, 897-911.

Duda, T.F., Lynch, J.F., Newhall, A.E., Wu, L., Chiu, C.S., 2004. Fluctuations of $400 \mathrm{~Hz}$ sound intensity in the 2001 ASIAEX South China Sea experiment. IEEE Journal of Oceanic Engineering 29 (4), $1264-$ 1279.

Holliday, D., McIntyre, M.E., 1981. On potential energy density in an incompressible, stratified fluid, Journal of Fluid Mechanics 107, 221-225.

Hsu, M.K., Liu, A.K., 2000. Nonlinear internal waves in the South China Sea, Canadian Journal of Remote Sensing 26, 72-81.

Helfrich, K. R., Melville, W.K., 1986. On long nonlinear internal waves over slope-shelf topography. Journal of Fluid Mechanics 167, 285-308.

Klymak, J.M., Pinkel, R., Liu, C.T., Liu, A.K., David, L., 2006. Prototypical solitons in the South China Sea. Geophysical Research Letters 33, L11607, doi:10.1029/ 2006GL025932.

Leichter, J.J., Deane, G.B., Stokes, M.D., 2005. Spatial and temporal variability of internal wave forcing on a coral reef, Journal of Physical Oceanography 35, 1945-1962, doi: 10.1175/JPO2808.1.

Li, Q., Farmer, D.M., 2011. The generation and evolution of nonlinear internal waves in the deep basin of the South China Sea. Journal of Physical Oceanography 41, 1345-1363.

Liu, A.K., Chang, Y.S., Hsu, M.K., Liang, N.K.,1998. Evolution of nonlinear internal waves in the East and South China Sea. Journal of Geophysical Research 103, C4, 7995-8008.

Moum, J.N., Klymak, J.M., Nash, J.D., Perlin, A., Smyth, W.D., 2007. Energy transport by nonlinear internal waves. Journal of Physical Oceanography 37, 1968-1988.

Orr, M.H., Mignerey, P.C. 2003. Nonlinear internal waves in the South China Sea: Observation of the conversion of depression internal waves to elevation internal waves. Journal of Geophysical Research 108, 3064, doi:10.1029/2001JC001163. 
Putnam, H.M., Edmunds P.J., Fan T.Y., 2010. Effect of a fluctuating thermal regime on adult reef corals and their larvae. Invertebrate Biology 129, 199-209.

Ramp, S.R., Tang, T.Y., Duda, T.F., Lynch, J.F., Liu, A.K., Chiu, C.S., Bahr, F.L., Kim, H.R., Yang, Y.J., 2004. Internal solitons in the Northeastern South China Sea Part I: source and deep water propagation. IEEE Journal of Oceanic Engineering 29, 1157-1181.

Ramp, S.R., Yang, Y.J., Bahr, F.L., 2010. Characterizing the nonlinear internal wave climate in the northeastern South China Sea. Nonlinear Processes in Geophysics 17, 481-498.

Shaw, P.T., Ko, D.S., Chao, S.Y., 2009. Generation of internal solitary waves in the northern South China Sea. Journal of Geophysical Research 114, C02019, doi:10:1029/2008JC004797.

Shroyer, E.L., Moum, J.N., Nash, J.D., 2009. Observations of polarity reversal in shoaling nonlinear internal waves. Journal of Physical Oceanography 39, 691-701.

Shroyer, E.L., Moum, J.N., Nash, J.D., 2010. Energy transformations and dissipation of nonlinear internal waves over New Jersey's continental shelf. Nonlinear Processes in Geophysics 17, 345-360.

St. Laurent, L., 2008. Turbulent dissipation on the margins of the South China Sea. Geophysical Research Letters 35, doi:10.1029/2008GL035520.

Vallis, G.K., 2006. Atmospheric and Oceanic Fluid Dynamics. Cambridge University Press, 745.

Vlasenko, V.,Stashchuk N., and Hutter K., 2002: Water exchange in fjords induced by tidally generated internal lee waves. Dynamics of Atmospheres and Oceans 35, 63-89.

Vlasenko, V., Stashchuk, N., 2007. Three-dimensional shoaling of large-amplitude internal waves. Journal of Geophysical Research 112, C11018. doi:10.1029/2007JC004107.

Wang, Y.H., Dai, C.F., Chen, Y.Y., 2007. Physical and ecological processes of internal waves on an isolated reef ecosystem in the South China Sea. Geophysical Research Letters 34, doi:10.1029/2007GL030658.

Warn-Varnas, A., Hawkins, J., Lamb, K.G., Piacsek, S., Chin-Bing, S., King, D., Burgos, G., 2010. Solitary wave generation dynamics at Luzon Strait. Ocean Modelling 31, 9-27

Zhao, Z., Klemas, V., Zheng Q., Yan, X.H., 2004. Remote sensing evidence for baroclinic tide origin of internal solitary waves in the northeastern South China Sea. Geophysical Research Letters 31, L06302, doi:10.1029/2003GL019077.

Zhao, Y., Liu, A.K., and Hsu, M.K., 2008. Internal wave refraction observed from sequential satellite images. Int. Journal of Remote Sensing 29, 6381-6390.

Zhang, Z., Fringer, O.B., Ramp, S.R., 2011.Three-dimensional, nonhydrostatic numerical simulation of nonlinear internal wave generation and propagation in the South China Sea. Journal of Geophysical Research 116, C05022. doi:10.1029/2010JC006424. 


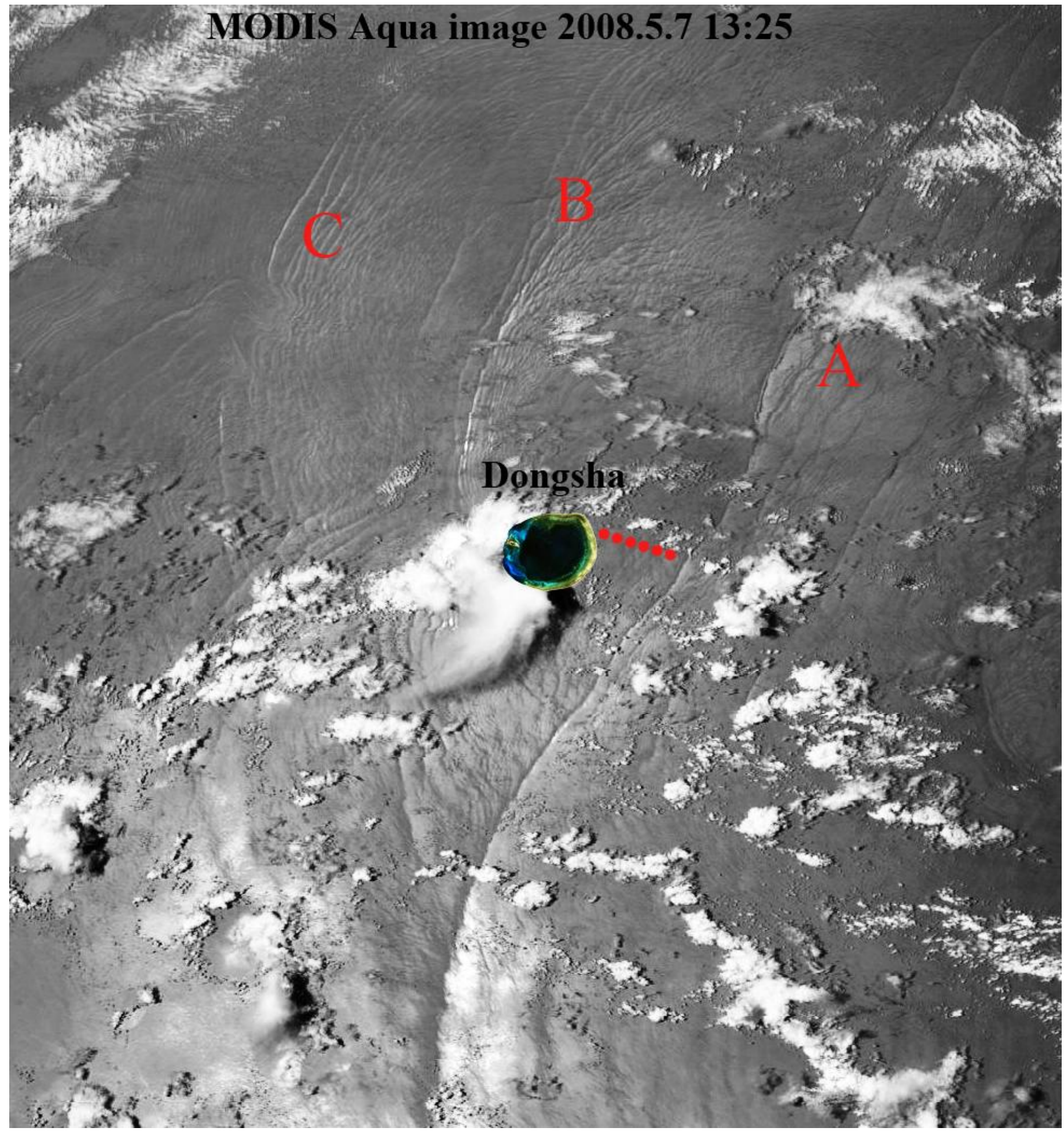

Figure 1. MODIS image near Dongsha Atoll of South China Sea on 13:25Z May 72008 (UTC+8). The diameter of the atoll is about $25 \mathrm{~km}$. Three groups (A, B, and C) of nonlinear internal waves are identified on the image with each group separated by $12 \mathrm{~h}$. The dotted line marks the orientation of the mooring line. The B-group corresponds to the May 7 event. 


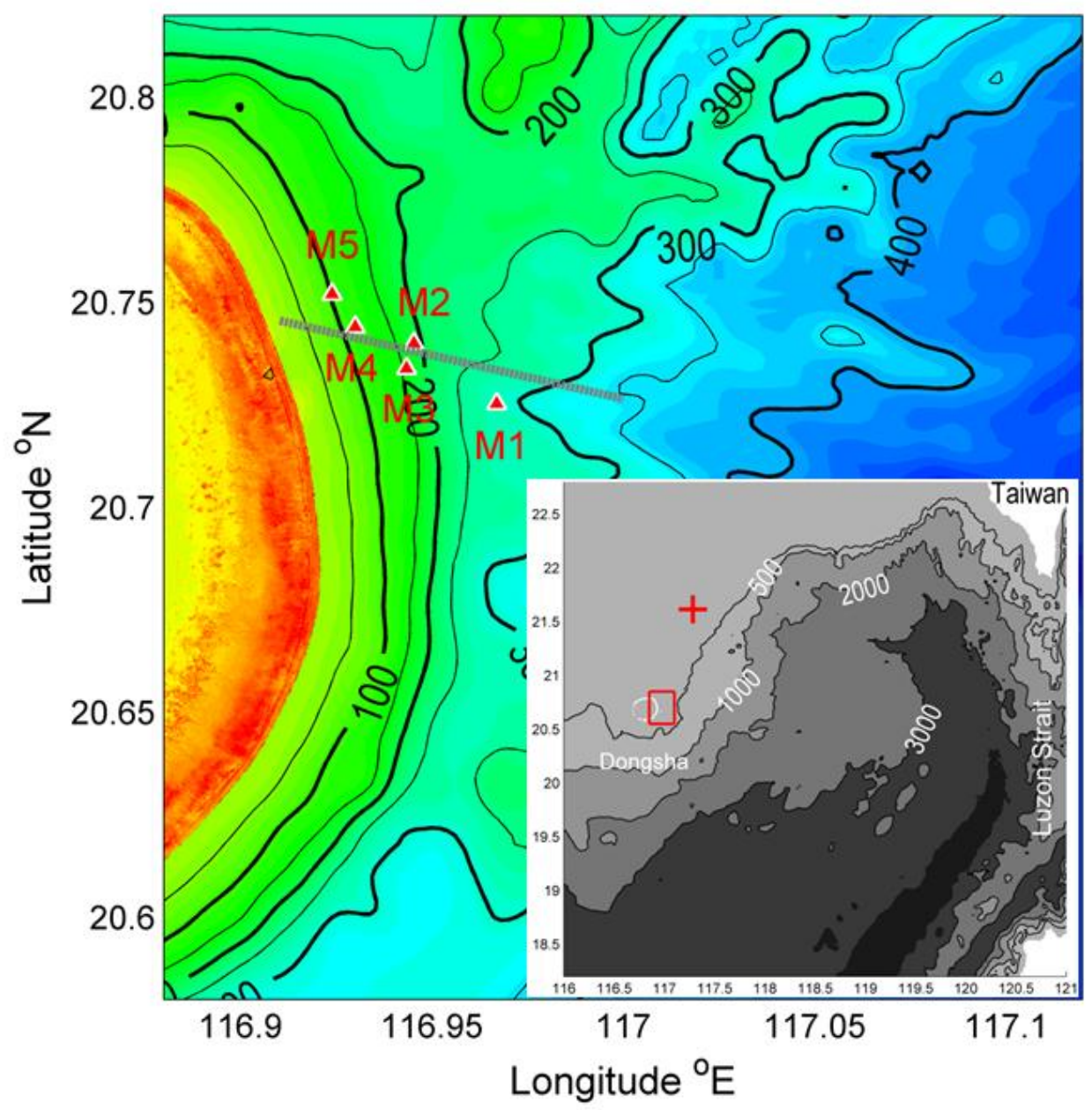

Figure 2. Map of depth contours east of the Dongsha Atoll with the mooring stations marked, M1 to M5 in water depths of $285 \mathrm{~m}, 195 \mathrm{~m}, 155 \mathrm{~m}, 110 \mathrm{~m}$ and $100 \mathrm{~m}$. The dashed line marks the orientation of the mooring line. The insert shows map of the northern South China Sea. Dongsha Atoll is located about $400 \mathrm{~km}$ southwest of Taiwan. The ASIAEX site (+) is about $100 \mathrm{~km}$ north of Dongsha Atoll. 


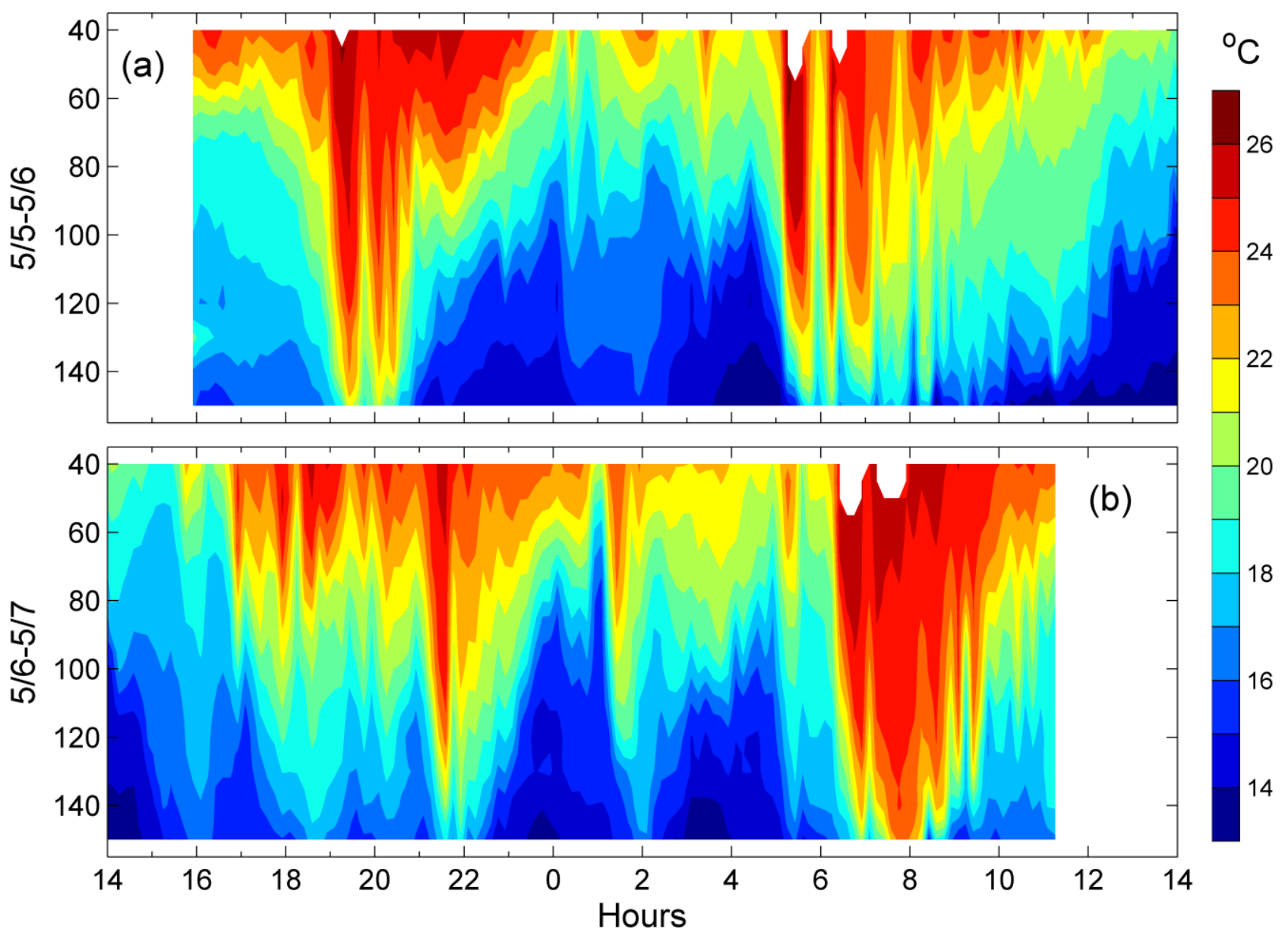

Figure 3. Stacked temperature contours at M3 from May 5 16:00Z to May 7 12:00Z, 2008. Each panel is one day $(24 \mathrm{~h})$ long. The vertical axis is the depth $(\mathrm{m})$. 


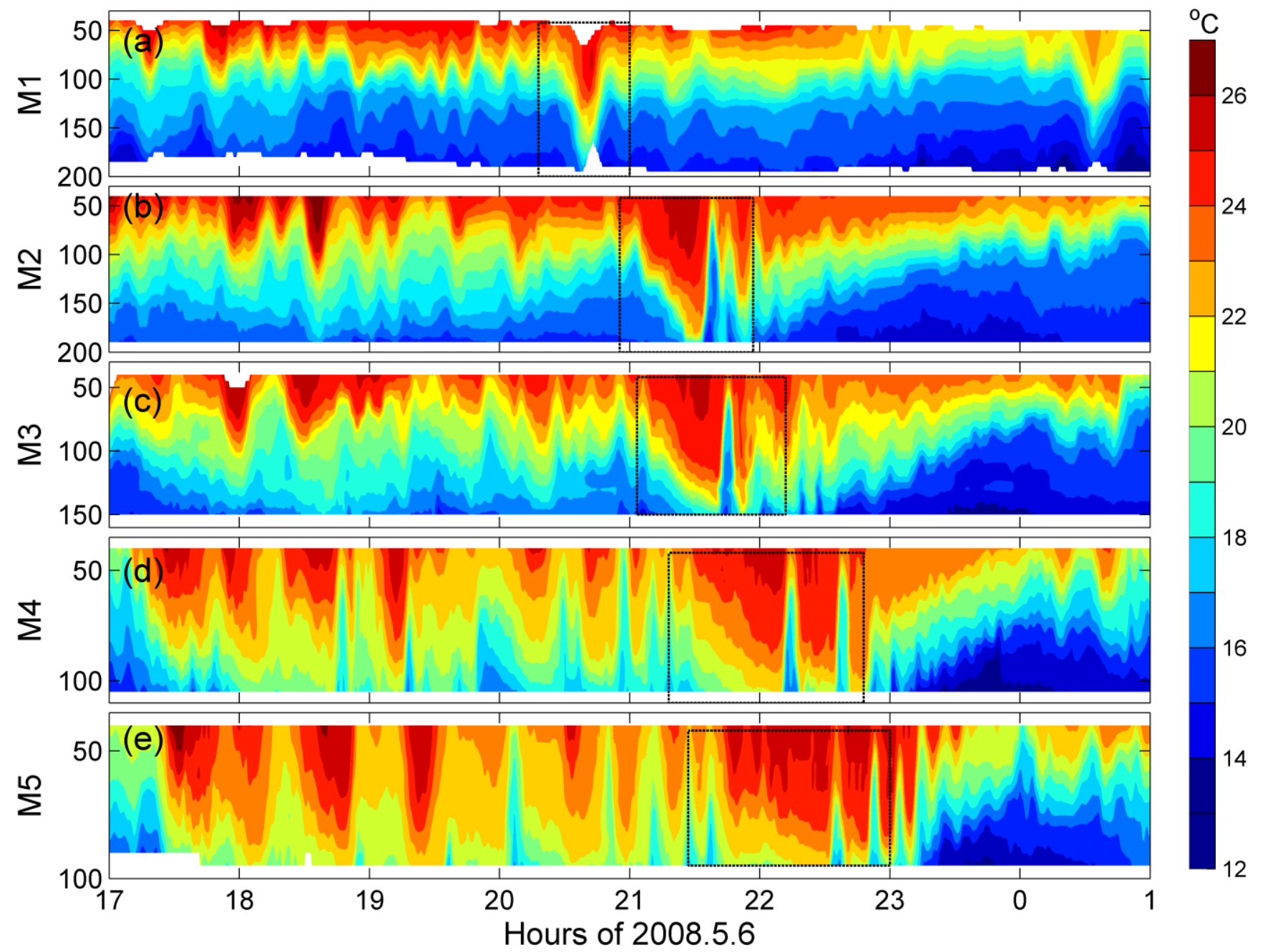

Figure 4. Temperature time series at the five mooring stations (M1-M5) in the evening of May 6, 2008. The black boxes mark the transition event. The vertical axis is the depth (m). 


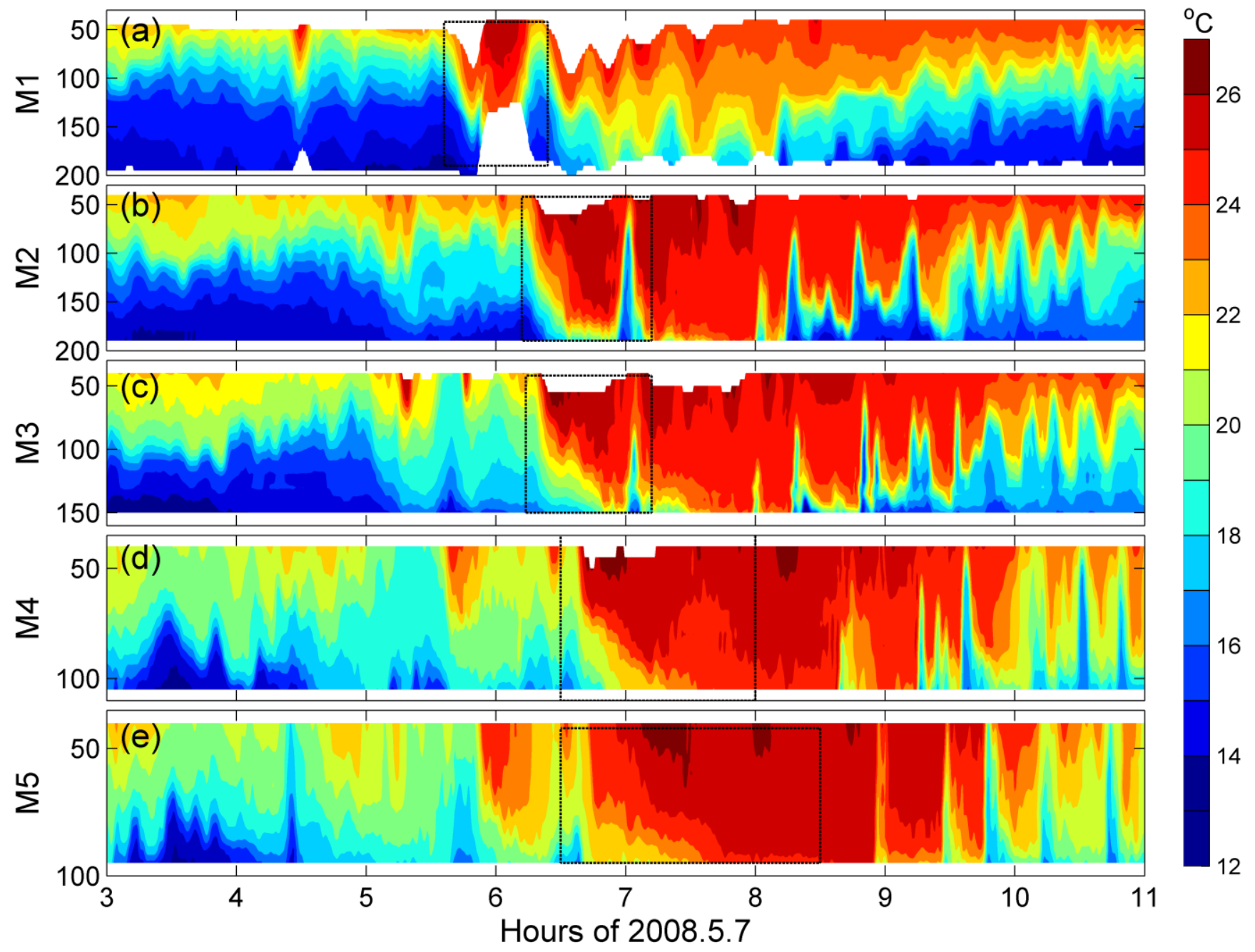

Figure 5. Temperature time series at the five mooring stations (M1-M5) in the morning of May 7, 2008. The black boxes mark the transition event. The vertical axis is the depth (m). 


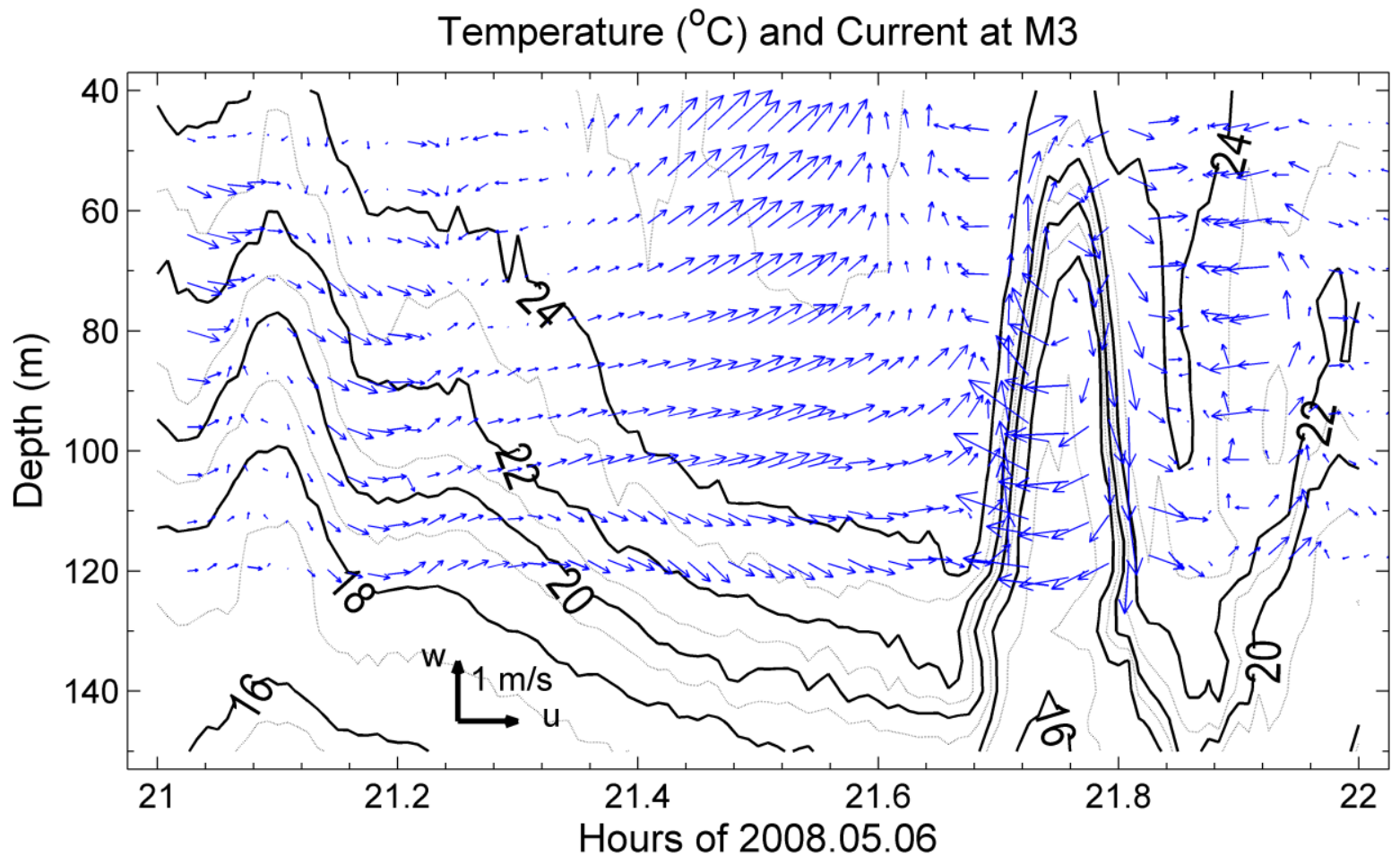

Figure 6. An expanded view (1-h duration) of currents (vectors) and temperatures (contours; $\left.{ }^{\circ} \mathrm{C}\right)$ at station M3 during the May 6 event. The positive u-component is eastward (offshore) and the positive w-component is upward. 


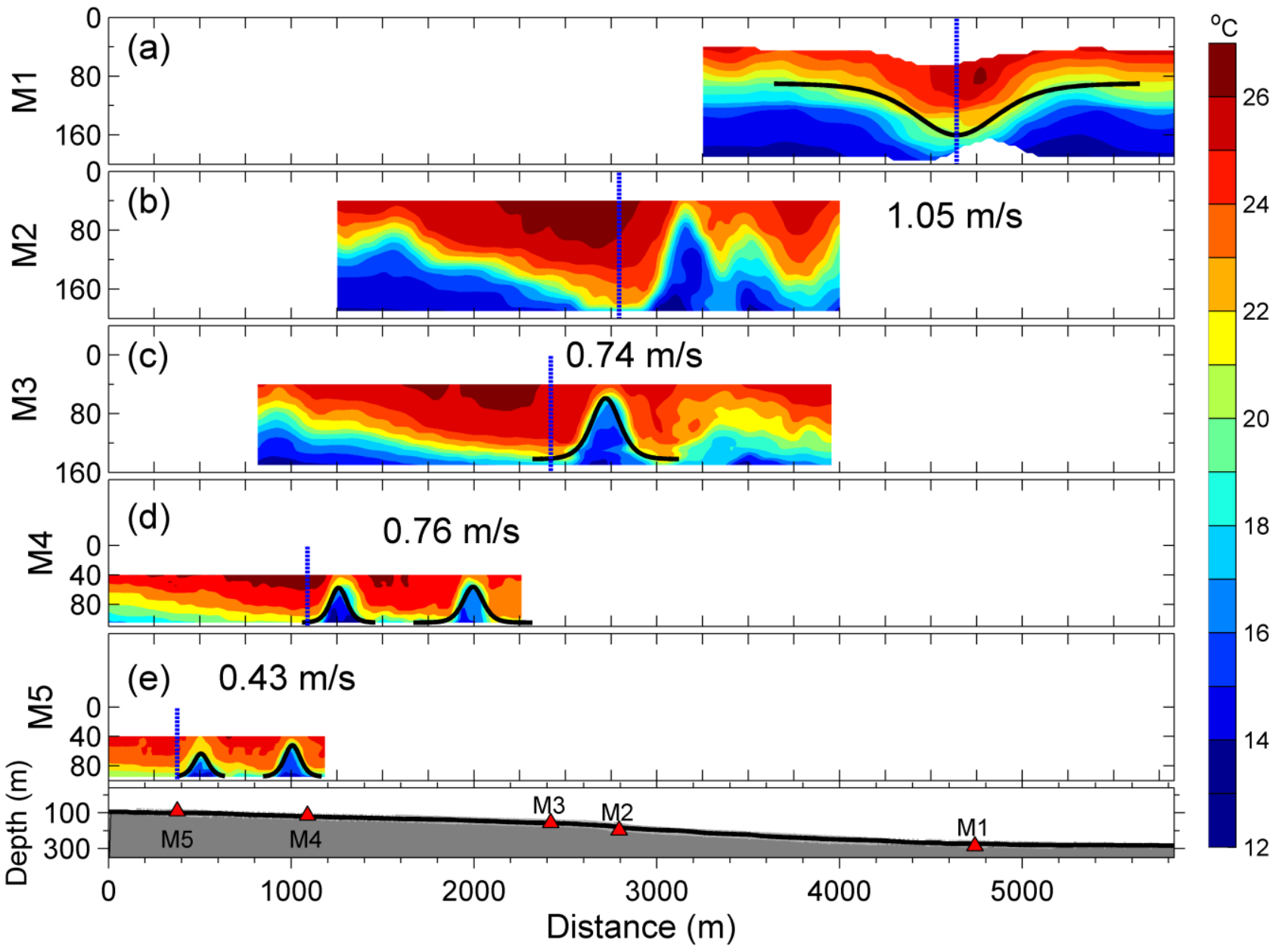

Figure 7. The May 6 event displayed in the distance coordinate. The thick black lines indicate the waveform fitted with the KdV solution. The estimated phase speeds between the two stations are indicated. The dotted vertical lines track the wave front. The station locations are marked in the bottom panel. 


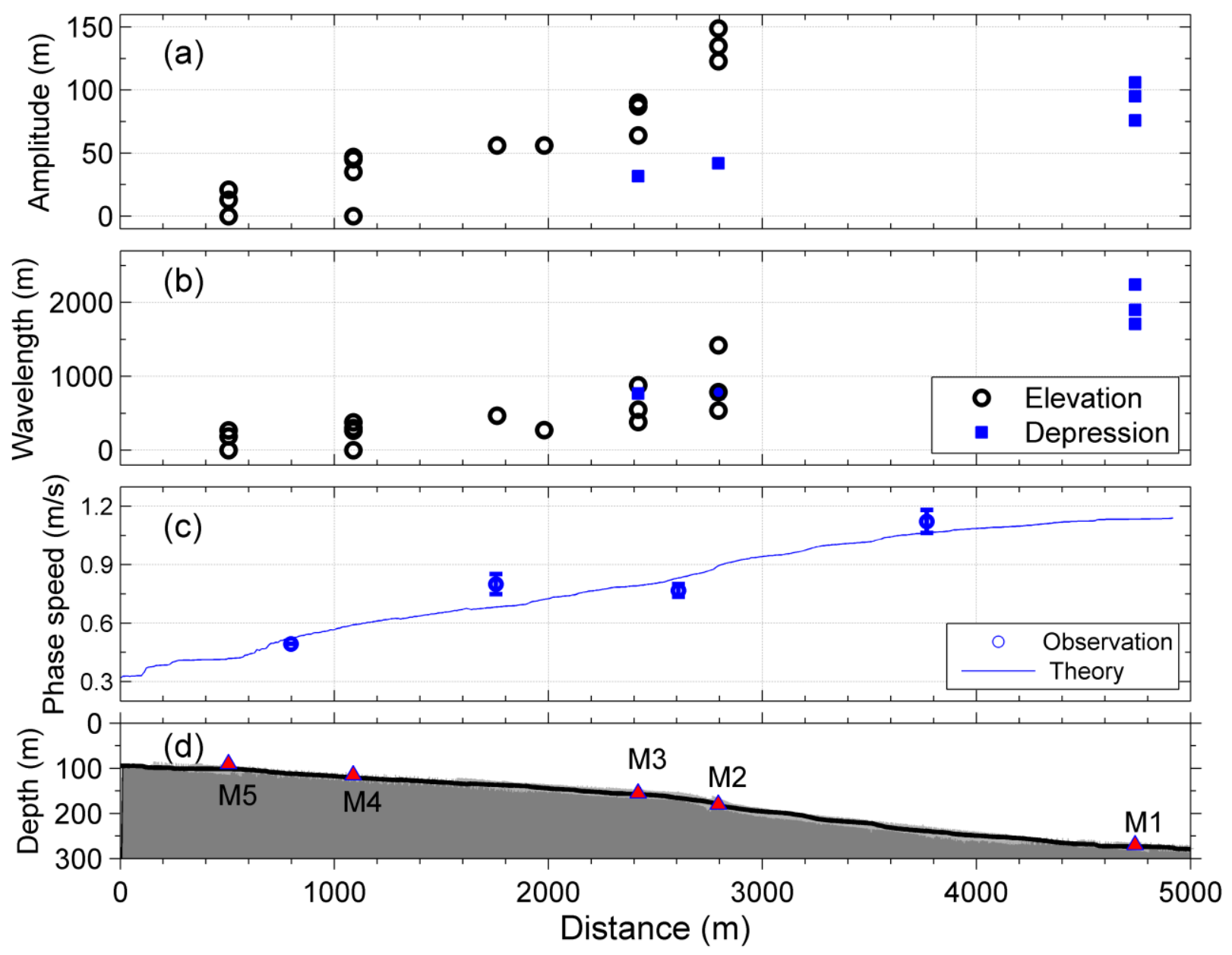

Figure 8. (a) Wave amplitudes and (b) wavelengths from fitting the depression and elevation waves to the $\mathrm{KdV}$ solution, and (c) phase speeds from observations (the mean and standard are indicated) and KdV theory, and (d) station locations. The elevation waves are marked with open circles $(\circ)$ and the depressions with solid squares ( $\mathbf{\square}$ ). 